\title{
COMPRESSIVE CRUSH PERFORMANCE OF SQUARE TUBES FILLED WITH SPHERES OF CLOSED-CELL ALUMINUM FOAMS
}

\begin{abstract}
This paper describes the compressive crush behaviour of spheres of closed-cell aluminium foams with different diameters $(6,8$ and $10 \mathrm{~mm})$ and square tubes filled with these spheres. The spheres of closed-cell aluminium foams are net spherical shape fabricated via powder metallurgy methods by heating foamable precursor materials in a mould. The square tubes were filled by pouring the spheres of closed-cell aluminium foams freely (without any bonding). The compressive crush performance of square tubes filled with spheres of closed-cell aluminum foams were compared to that of the empty tubes. The results show a significant influence of the spheres of closed-cell aluminium foam on the average crushing load of the square tubes. The energy absorption in the square tube filled with spheres of closed-cell aluminium foam with diameters of $10 \mathrm{~mm}$ is higher than in the other square tubes. The spheres of closed-cell aluminium foams led to improvement of the energy absorption capacity of empty tubes.
\end{abstract}

Keywords: Spheres of closed-cell aluminium foam; foam-filled tubes; compression behavior; energy absorption

\section{Introduction}

Recently, there has been increased concern regarding aluminium alloy foams owing to their properties of low density, high damping and impact energy absorption capacity. These materials have many applications in aerospace, automotive, biomedical and engineering industries in general [1-3]. They are capable of transforming the impact energy of deformations and can absorb more energy than bulk materials at a lower strain $[4,5]$. In particular, the use of aluminium foams as filling materials in structural compositions has been designed and developed [1]. Cellular fillers are usually designed in order to increase energy absorption to reduce sound/vibration or simply to make it possible for sandwich and hollow structures to perform better as a simple light core layer [6-10].

The study of crash boxes and bumpers made of hollow aluminium or steel revealed positive results when aluminium foam was used for reinforcement [11]. Many experimental studies have been performed on aluminium foams and tubes with foam cores [12-19]. Duarte et al. [7-10,20] investigated several deformation modes and failure mechanisms for ex-situ and in-situ foam-filled tubes made of aluminium alloys under quasi-static and dynamic compression and bending loads. Results of the study emphasizes the importance of the reaction occurred between the foam and the tube. Guden and Kavi [17] examined the axial crushing behaviour of empty and closed-cell aluminium foam-filled multi-tube designs under axial compressive stress for several states. They found that multi-tubes are more effective than single tubes with respect to the level of energy absorption. Toksoy and Guden [21] suggested that foam filler changes the mode of deformation of the tube (from multi-lobe mode to symmetrical mode) which in turn reduces the folding performance. Hall et al. [18] examined energy absorption of Al foam-filled and empty tubes made of aluminium, brass, and titanium.

The spheres of closed-cell aluminium foams, called Advanced Pore Morphology (APM) foam, have become of interest due to their simple geometries that can be easily produced [22-26]. The APM foams first started to be produced at the IFAM Fraunhofer Institute in Bremen, Germany. The production process involves heating the small rectangular precursor elements in a continuous belt furnace [22]. The APM foam parts are closed-cell aluminium foams of approximate spherical shape of a diameter from 2 to $15 \mathrm{~mm}$, which are fabricated by using the conventional powder metallurgy method [22,25-27]. Duarte and Ferreira studied the 2D quantitative analysis of metal foaming kinetics by hot stage microscopy. They demonstrated that the surface tension force, which is relatively greater than in the hydrostatic pressure, provides the formation of approximate spherical foam pieces during the melting process [26,28]. However, the samples are not perfectly spherical as a result of the melting foam which is deformed due to the effect of gravity [24]. Therefore, the mechanical response of the foam parts may chance.

Recent studies focused on the mechanical properties of APM foam elements. For example, Lehmus et al. [29] explored the effects of the APM foam density using quasi-static and dynamic

* KASTAMONU UNIVERSITY, DEPARTMENT OF MECHANICAL ENGINEERING, KASTAMONU 37150, TURKEY

\# Corresponding author: auzun@kastamonu.edu.tr 
compression tests. Vesenjak et al. [30] investigated the axial crushing behavior of single APM foam elements and composite APM foam. Researchers have used infrared thermal imaging in order to identify the plastification zone in further advanced empirical tests. Nevertheless, micro computed tomography $(\mu \mathrm{CT})$ analysis was employed in order to assess the structural characterization and volumetrics voids of the APM foam elements. These studies evaluated the relationship between pore dimension distribution and their location in APM foam elements and pore geometry and the aluminium alloy [32,33]. Duarte et al. [26] investigated the uniaxial-compressive crush performance of thin-walled structures made of Al-alloy AA 6060 filled with Advanced Pore Morphology (APM) foam elements using polyamide as the bonding agent. Results of the study showed that a better adhesive bond between foam elements and tube improves the mechanical properties of the structure. Such a bond facilitates the load transfer from the tube to foam during compression.

The aim of the present work was to investigate the compressive crush behaviour of spheres of closed-cell aluminium foams with different diameters $(6,8$ and $10 \mathrm{~mm})$ and square tubes filled with these spheres. The square tubes were filled by pouring the spheres of closed-cell aluminium foams freely (without any bonding). The axial compressive crush performance of these square tubes was studied and evaluated by using uniaxial compression tests. The compressive crush performance of square tubes filled with spheres of closed-cell aluminum foams were then compared to that of the empty tubes.

\section{Experimental procedure}

\section{Preparation of the specimens}

In this study the powder metallurgy (PM) method was used to fabricate spheres of closed-cell aluminium foam filler. PM method [27,34], one of the most commonly used to fabricate the closed-cell metal foams, consists on heating of a foamable precursor material obtained by compaction of a metal alloy (e.g., Al-alloy) with blowing agent powders (e.g., titanium hydride, $\mathrm{TiH}_{2}$ ). In experimental studies, air atomized $\mathrm{Al}$ powder (ECKA Granules) with particle size $<160 \mu \mathrm{m}, 7$ wt. \% Si powder (Atlantic Equipment Engineers) with particle size $<44 \mu \mathrm{m}$ and $1 \mathrm{wt} . \%$ $\mathrm{TiH}_{2}$ powder was supplied from Sigma-Aldrich were used as the starting materials. The starting materials were blended in a three-dimensional mixer for $30 \mathrm{~min}$. The mixture powders were cold compacted inside a steel die under a pressure of $400 \mathrm{MPa}$ to produce PM block samples with diameter of $62 \mathrm{~mm}$ (Fig. 1a). These samples were pre-sintered to achieve a more intense structure and to facilitate extrusion at a temperature of $550^{\circ} \mathrm{C}$. The extrusion process (extrusion rate $=1: 4$ ) was carried out at $550^{\circ} \mathrm{C}$ before rolling in order to produce foamable precursor samples with a $25 \times 30 \mathrm{~mm}^{2}$ cross-sectional area (Fig. 1b). The rolling process were applied to the extruded foamable precursor materials in order to obtain sheets with different thickness $(\sim 2,3$ and $5 \mathrm{~mm}$ ) (Fig. 1c). The precursor material was then cut into pieces to the dimensions shown in Figure 1c. These pieces were placed in steel moulds with diameters of 6,8 and $10 \mathrm{~mm}$. This mould is composed of two parts (Fig. 2a). There are holes on the upper part (number 1) of the foaming mould. These holes are very important for the completion of the foaming process as the process controls were carried out through these holes. The mould was put in the resistance furnace which had been preheated to a certain temperature $\left(710^{\circ} \mathrm{C}\right)$ (Fig. $\left.2 \mathrm{~b}\right)$. The precursor started to foam after it was heated for a certain time. Subsequently, it took the shape of the mould and then overflew from the holes on the upper part of the foaming mould. At this point the mould was taken out of the furnace and cooled in air, and finally, the net-shaped spheres of closed-cell aluminium foam with different diameters $(6,8$ and $10 \mathrm{~mm})$ were obtained (Fig. 2c). Thus, the foam parts with excellent spherical shapes were obtained and the size control could be done easily. The spheres of closed-cell aluminium foam parts then filled by pouring into the square tubes made of structural steel (St 37), which have a cross section of $25 \times 25 \mathrm{~mm}^{2}$, wall thickness of $1 \mathrm{~mm}$, and length of $50 \mathrm{~mm}$

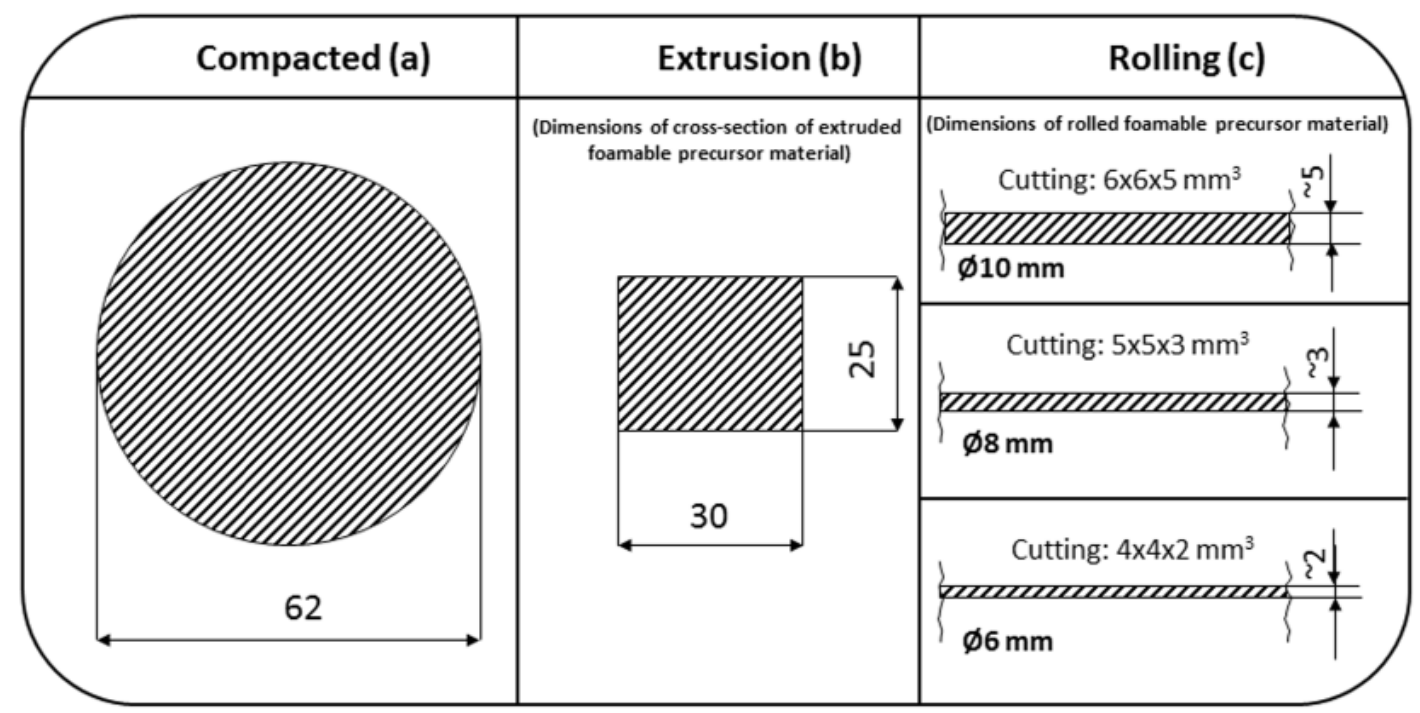

Fig. 1. Schematic view of sample cross-sections at various production stages; a) compacting, b) extrusion, c) rolling 


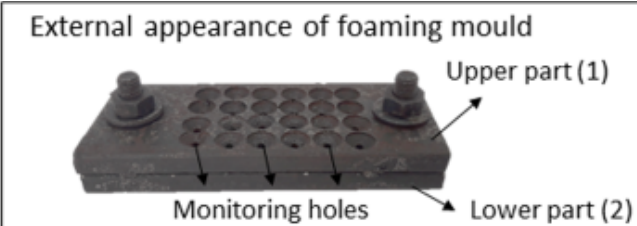

Interior appearance of foaming mould

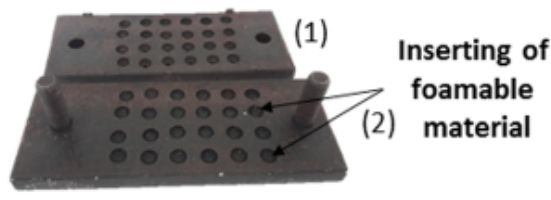

Foaming mould (a)

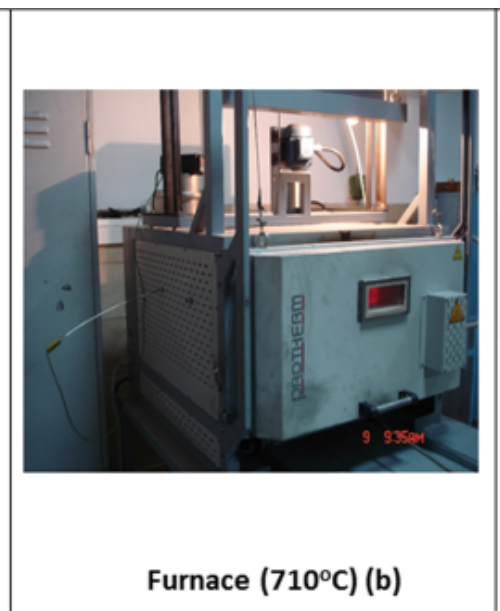

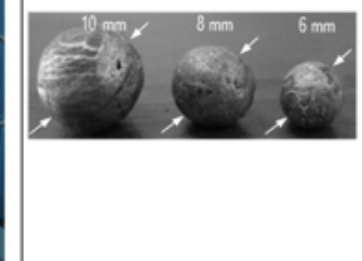

Spheres of closedcell aluminium foams (c)

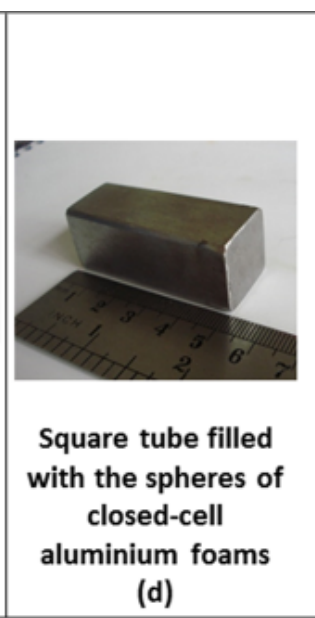

(d)

Fig. 2. Foaming mould (a), furnace (b), spheres of closed - cell aluminium foams with different diameters (D: 6, 8 and $10 \mathrm{~mm}$ ) (c), square tube filled with the spheres of closed - cell aluminium foams

(Fig. 1c). After the filling, the ends of the square tubes was closed with steel sheets made of structural steel (St 37) which had a cross section of $25 \times 25 \mathrm{~mm}^{2}$, wall thickness of $1 \mathrm{~mm}$ (Fig. 2d). For this operation, welding seams form a point-to-point produced by metal inert gas (MIG) welding process was used. The aim is to prevent the fall of the foam pieces.

\section{Mechanical characterisation}

The experimental testing was divided into two parts: (1) characterization of single sphere of closed-cell aluminum foam and (2) characterization of the square tubes filled with spheres of closed-cell aluminum foams with empty tubes. Uniaxial compression tests (loading rates for tubes and single spheres of closed-cell aluminium foam were 10 and $1 \mathrm{~mm} \mathrm{~min}^{-1}$, respectively) were performed on the samples with an Instron 3369 testing machine to evaluate the foam filling effect. At least four samples for each experimental process were tested.

\section{Results and discussion}

\section{Compressive behaviour of individual spheres of closed-cell aluminum foams}

Figure 3 shows the sphere of closed-cell aluminum foam with diameter of $10 \mathrm{~mm}$ at various compression states (a) and average force-strain curves (b) of spheres of closed-cell aluminum foams with different diameters $(6,8$ and $10 \mathrm{~mm})$. Initially, the contact points between the foam and the compression punch depended on the deformation of the spheres of closedcell aluminum foams [24]. The formation of cracks in the outer surface layer of the samples began at $40 \%$ deformation. These cracks can be seen at higher deformation rates. However, they are not necessarily detectable because of geometry changes in the deformed samples. The force level increase in samples with high density is seen to be higher. The increase in the volume or diameter corresponded to the increased resistance to deformation and strength [35]. The deformation is not uniform because of the constantly changing geometry of the samples in the load direction, which started at the contact of the samples with the
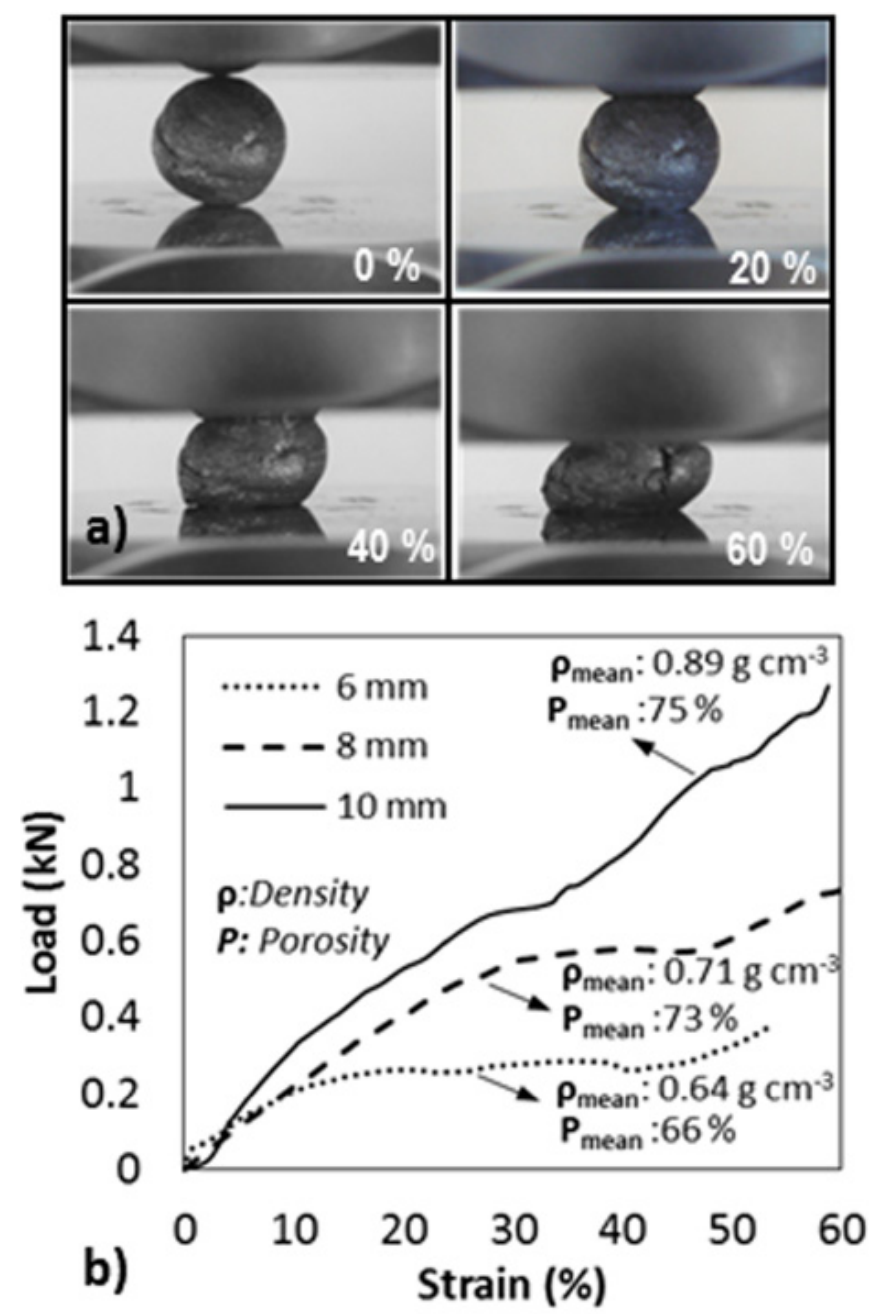

Fig. 3. Images of the sphere of closed-cell aluminium foam with diameter of $10 \mathrm{~mm}$ at various compression stages (a) and average force-strain curves (b) of spheres of closed-cell aluminium foams with different diameters $(6,8$ and $10 \mathrm{~mm})$ 
clamping plates. Then, very small changes in cross-sectional areas of samples occurred with plastic deformation. The rapid increase in the level of deformation, however, inevitably led to strain hardening and the formation of cracks in the outer surface layer. Although this outer surface layer in the spheres of closedcell aluminum foams provides structural resistance during the deformation, irregularity of the cellular structure can break this resistance. A study by Stöbener et al. [24] reported that the volume/diameter ratio has no significant effect on stress.

\section{Compressive behaviour of square tubes filled with spheres of closed-cell aluminium foams}

Figure 4 shows the compression load-displacement curves of the spheres of closed-cell aluminium foams-filled tubes and the empty tube. Crush images taken during the deformation are shown on the same curves. The mean load values of each sample were constantly increased and decreased as seen in the Figures $4 \mathrm{a}-\mathrm{c}$. The average load values of the empty tubes were represented by the gray line. The peak value of the first load

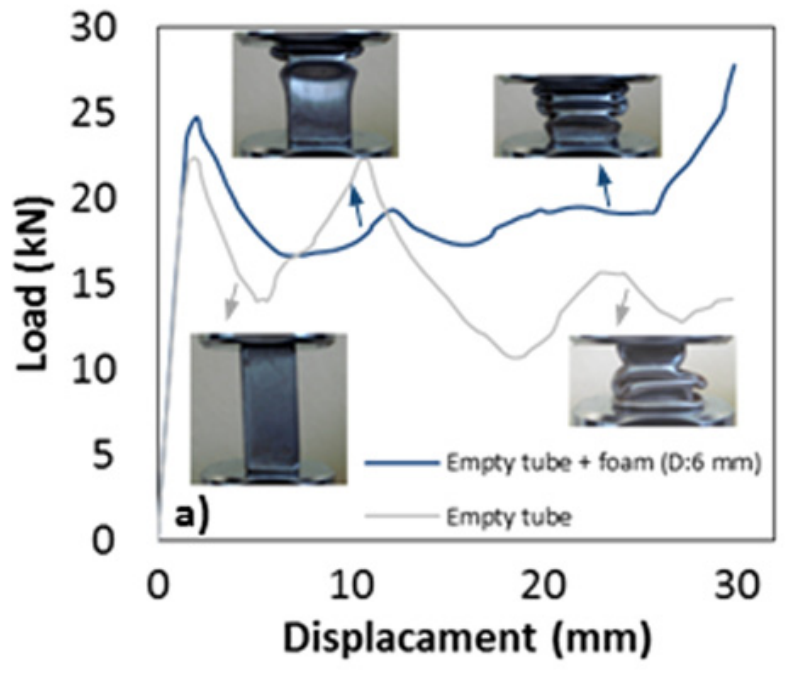

for the empty tube is similar to the value of the next load, and from that point on, the load was decreased. The maximum value of the crush can be considered to be $22 \mathrm{kN}$. Empty tubes were crushed with an average load of $15 \mathrm{kN}$. The crushing behaviour of the spheres of closed-cell aluminium foams-filled tubes is different from that of the empty tubes. However, the first crush load values were changed owing to the difference in the volume of aluminium foam spheres. The first loads to instantly crush the spheres of closed-cell aluminium foams with diameters of 6,8 and $10 \mathrm{~mm}$ in the filled tubes averaged 25,23 and $23 \mathrm{kN}$, respectively. The folding of the squared tubes with the addition of $6 \mathrm{~mm}$ diameter foam and the empty tubes started from one end towards the other end of the tube and progressed (Fig. 4a). However, the folding of the square tubes filled with spheres of closed-cell aluminium foams with diameters of 8 and $10 \mathrm{~mm}$ started at either end of the tube (Figs. 4b,c). The empty tubes were folded symmetrically, but axial differences in the filled tubes were observed. This is because volume cavity irregularities and non-homogeneous dispersion of sphere of closed-cell aluminium foam fillers can be shown in the square tubes. Moreover, it may result from the lack of an interface bond between spheres of

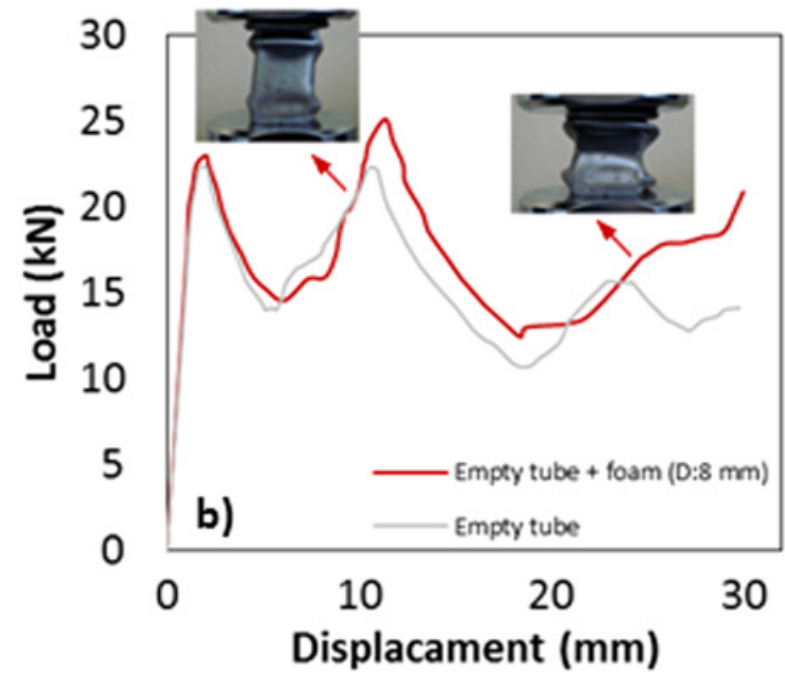

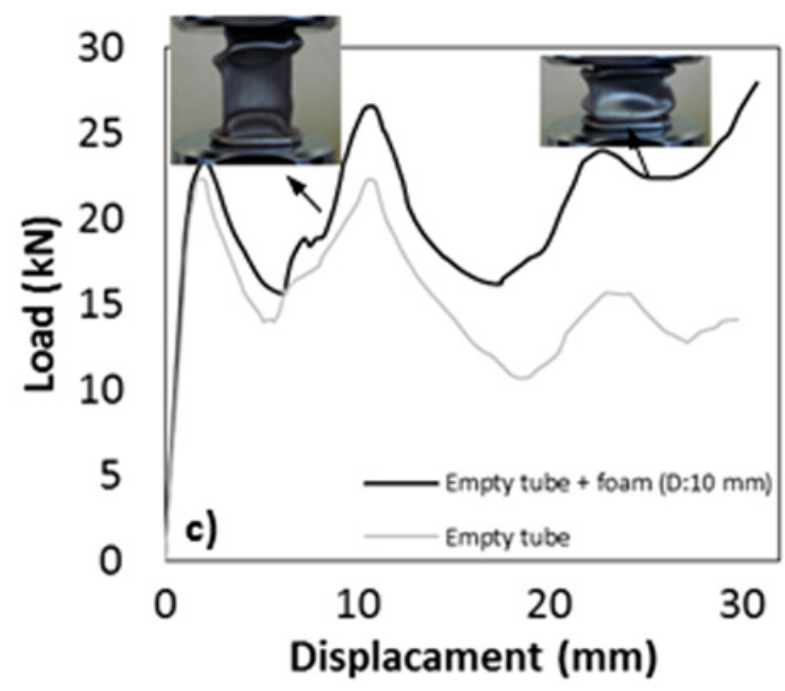

Fig. 4. Compression load-displacement curves of the spheres of closed-cell aluminium foams-filled tubes and the empty tube; a) Empty tube + foam (D: $6 \mathrm{~mm})$, b) Empty tube + foam (D: $8 \mathrm{~mm})$, c) Empty tube + foam (D: $10 \mathrm{~mm})$ 
closed-cell aluminium foams and tube walls. Duarte [10] reported that formation of a better interface bond between tube and foam filler will contribute to axial symmetrical deformation without distortion while the lack of interface bond leads to an irregular folding with a certain distortion. The literature provides several studies on the buckling behavior of steel and aluminium alloy profiles. Additionally, it is known that buckling behavior depends mainly on the material (e.g. chemical composition and mechanical properties) and geometrical (e.g. cross-section diameter, wall thickness and height) properties [9,36-38].

\section{Energy absorption capabilities}

The energy absorption $(E A)$ of samples were evaluated with the integral of the area under the load-displacement curve (Fig. 4). This value was calculated by the formula given in Equation (1), where $\delta$ and $\mathrm{F}$ are the displacement and the load, respectively.

$$
E A(\delta)=\int_{0}^{\delta} F(\delta) d \delta
$$

The corresponding average crushing load $\left(F_{a}\right)$ is calculated dividing the absorbed energy by the displacement (Equation 2).

$$
F_{a}=\frac{E A(\delta)}{\delta}
$$

The energy absorption in the square tube filled with spheres of closed-cell aluminium foam with diameters of $10 \mathrm{~mm}$ is higher than in the other metal tubes as shown in Fig. 5. The spheres of closed-cell aluminium foams led to a small improvement of the energy absorption capacity of empty tube. The average crushing loads of the tubes containing spheres of closed-cell aluminium foams with diameters of 6,8 and $10 \mathrm{~mm}$ were 19,21 and $26 \mathrm{kN}$, respectively. Additionally, the energy absorption increases with the increase of the foam filer density of foam-filled tubes $[9,10]$. However, the volumetric voids between the spheres of closedcell aluminium foam filler and the square tube might provide a relatively negative contribution and uncontrolled energy absorption (Fig. 6). This situation is related to the interaction between the spheres of closed-cell aluminium foam filler and the inner walls of square tubes. Asavavisithchai et al. [12] reported that the bonding strength between the foam filler and the tube wall has no significant effect on the energy absorbed during the compressive crushing test. Duarte et al. [8] used an adhesive for a strong bonding between the foam core and the inner tube wall. The strong bonding between the foam core and the inner tube wall is effective in load transfer from the tube to the foam core, leading to an increase in the energy absorption capability. In this study, however, the square tubes filled by pouring the spheres of closed-cell aluminium foams freely (without any bonding). Thus, a strong bonding between the spheres of closed-cell aluminium foam filler and the inner tube wall was not obtained compared to in-situ foam filled tubes.

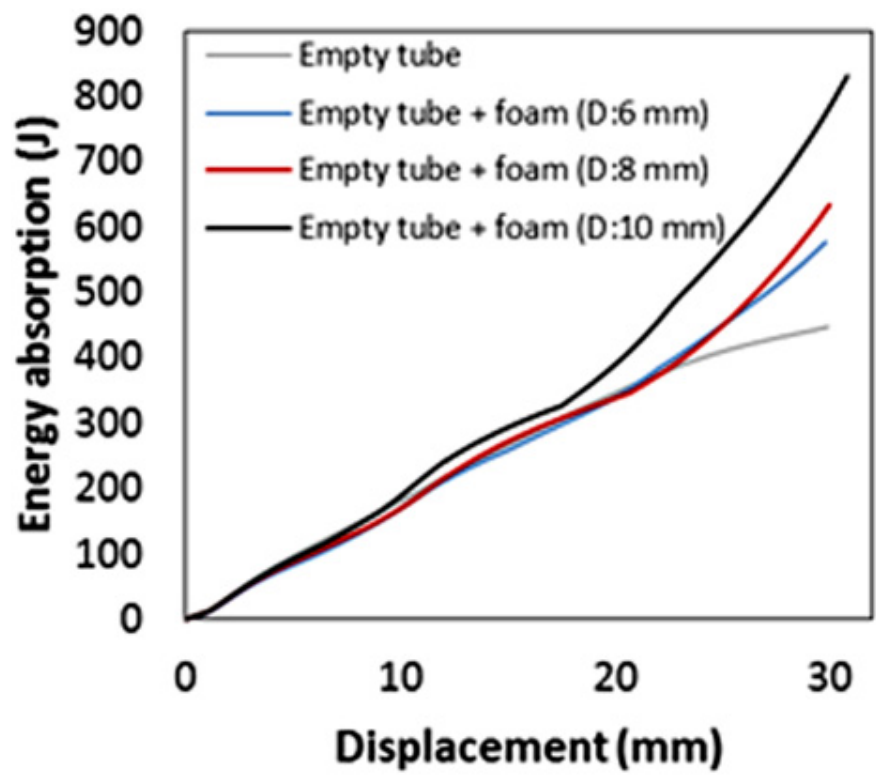

Fig. 5. Energy absorption values of square tubes filled with spheres of closed-cell aluminium foams with different diameters $(6,8$ and $10 \mathrm{~mm})$

\section{Conclusions}

The compressive crush performance of square tubes made of structural steel (St 37) filled with non-bonded spheres of closed-cell aluminium foams with different diameters $(6,8$ and $10 \mathrm{~mm}$ ) were evaluated. The compressive crush performance

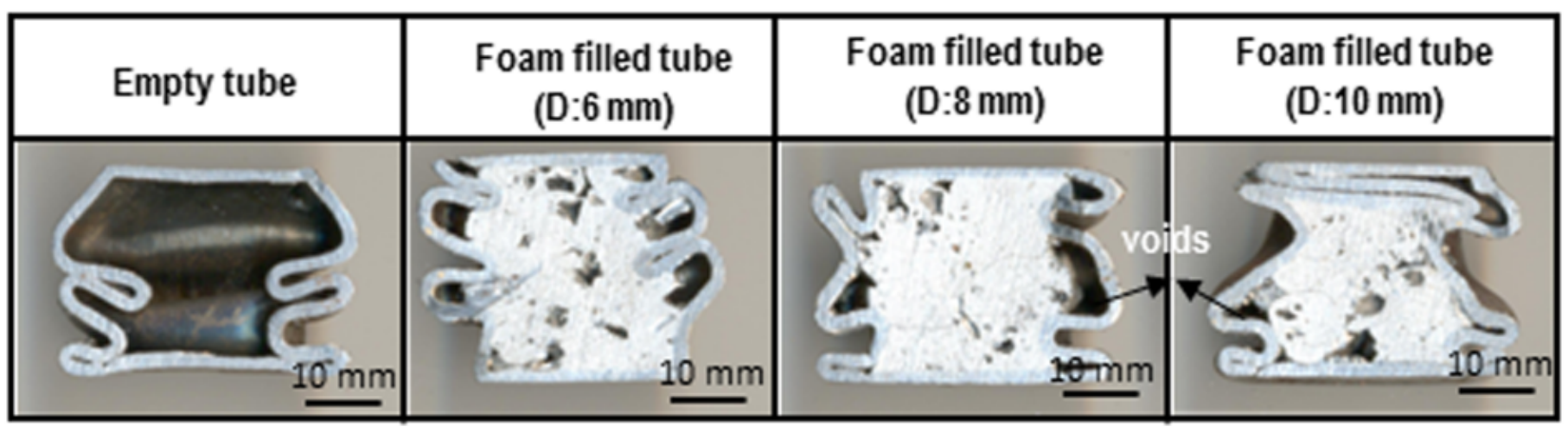

Fig. 6. Cross section of crushed square tubes filled with spheres of closed-cell aluminium foams with different diameters $(6,8$ and $10 \mathrm{~mm})$ 
of these structures were compared to that of the empty tubes. The spheres of closed-cell aluminium foams are an approximate spherical shape fabricated via the powder metallurgy methods by heating foamable precursor materials in a mould. The results show a significant influence of the spheres of closed-cell aluminium foam filling on the average crushing load of empty tubes. The energy absorption in the square tube filled with spheres of closed-cell aluminium foam with diameters of $10 \mathrm{~mm}$ is higher than in the other square tubes. Additionally, the energy absorption increases with the increase of the foam filer density of foamfilled tubes. The load transfer between the spheres of closed-cell aluminium foam filler and the inner tube wall was not uniform.

\section{REFERENCES}

[1] F.G. Moreno, 9 (2), 85 (2016).

[2] J. Banhart, Prog. Mater. Sci. 46, 559-632 (2001).

[3] D. Schwingel, H.W. Seeliger, C. Vecchionacci, D. Alwes, J. Dittrich, Acta Astronaut. 61 (1-6), 326-330 (2007).

[4] A.D. Kathryn, L. James, Mat. Sci. and Eng. A. 293, 157-164 (2000).

[5] Y. Liu, X. Gong, Trans. Nonferrous Met. Soci. of China 16, 439443 (2006)

[6] J. Banhart, H.W. Seeliger, Adv. Eng. Mater. 10 (9), 793-802 (2008).

[7] I. Duarte, M. Vesenjak, L.K. Opara, Compos. Struct. 109, 48-56 (2014).

[8] I Duarte, M. Vesensak, L.K. Opara, I. Anzel, J.M. Ferreira, Mater. Des. 66, 532-544 (2015).

[9] I. Duarte, L.K. Opara, M. Vesenjak, Compos. Struct. 121, 154-162 (2015).

[10] I. Duarte, M. Vesenjak, L.K. Opara, Compos. Struct. 124, 128-139 (2015).

[11] K. Ito, H. Kobayashi. Adv. Eng. Mater. 8, 828-835 (2006).

[12] S. Asavavisithchai, D. Slater, A.R. Kennedy, J. Mater. Sci. 39, 5873-5875 (2004).

[13] E.W. Andrews, G. Gioux, P.R. Onck, L.J. Gibson, Int. J. Mech. Sci. 43, 701-713 (2001)

[14] Y. Chino, M. Mabuchi, Y. Yamada, S. Hagiwara, H. Iwasaki, Mater. Trans. 44, 633-636 (2003).

[15] K.A. Dannemann, J. Lankford, Mater. Sci. and Eng. A. 293, 157$164(2000)$
[16] S.R. Guillow, G. Lu, R.H. Grezbieta, Int. J. Mech. Sci. 43, 20132023 (2001).

[17] M. Guden, H. Kavi, Thin-Walled Struct. 44, 739-750 (2006).

[18] I.W. Hall, M. Guden, T.D. Claar, Scrip. Mater. 46, 513-518 (2002).

[19] A.G. Hanssen, M. Langseth, O.S. Hopperstad, Inter. J. Mech. Sci. 43, 153-176 (2001).

[20] I. Duarte, L.K. Opara, M. Vesenjak, Compos. Struct. 152, 432-443 (2016).

[21] A.K. Toksoy, M. Guden, Thin-Walled Struct. 43, 333-350 (2005).

[22] K. Stöbener, J. Baumeister, G. Rausch, M, Rausch, Met. Powder Rep. 60 (1), 12-16 (2005).

[23] K. Stöbener, J. Baumeister, G. Rausch, M. Busse, High Temp. Mater. Processes 26 (4), 231-238 (2007).

[24] K. Stöbener, D. Lehmhus, M. Avalle, L. Peroni, M. Busse, Int. J. Solids Struct. 45, 5627-5641 (2008).

[25] K. Stöbener, G. Rausch, J. Mater. Sci. 44, 1506-1511 (2009).

[26] I. Duarte, M. Vesenjak, L.K. Opara, Z. Ren, Compos. Struct. 134, 409-420 (2015).

[27] F. Baumgärtner, I. Duarte, J. Banhart, Adv. Eng. Mater. 2 (4), 168-174 (2000).

[28] I. Duarte, J.M. Ferreira, Adv. Eng. Mater. 16 (1), 33-39 (2014).

[29] D. Lehmhus, J. Baumeister, L. Stutz, E. Schneider, K. Stöbener, M. Avalle, L. Peroni, M. Peroni, Adv. Eng. Mater. 12 (7), 596-603 (2009).

[30] M. Vesenjak, F. Gaćnik, L.K. Opara, Z. Ren, J. Compos. Mater. 45 (26), 2823-2831 (2011).

[31] M. Vesenjak, F. Gaćnik, L. K. Opara, Z. Ren, Mech. Adv. Mater. Struct. 22 (5), 359-366 (2015).

[32] M. Vesenjak, M. Borovinšek, T. Fiedler, Y. Higa, Z. Ren, Mater. Lett. 110, 201-203 (2013).

[33] M. Ulbin, M. Borovinšek, Y. Higa, K. Shimojima, M. Vesenjak, Z. Ren, Mater. Lett. 136, 416-419 (2014).

[34] I. Duarte, J. Banhart, Acta Mater. 48, 2349-2362 (2000).

[35] M. Vesenjak, L. Krstulovic, Proceeding 14th International Conference on Experimental Mechanics, Poitiers, France (2010).

[36] F. Bardi, H. Yun, S. Kyriakides, Int. J. Solids Struct. 40, 31373155, (2003).

[37] K.R.F. Andrews, G.L. England, E. Ghani, Int. J. Mech. Sci. 25, 687-696 (1983).

[38] M. Vesenjak, K. Hokamoto, M. Sakamoto, T. Nishi, L. K. Opara, Z. Ren, Mater. Des. 90, 867-880 (2016). 